\title{
Comunicação como Ciência Social (e mais)*
}

\author{
Craig Calhoun**
}

\section{Resumo}

A Comunicação é o campo mais importante para o estudo de muitas dimensões- chave de mudanças sociais. Esta é a premissa básica deste texto apresentado na conferência de abertura do congresso anual da International Communication Association, em 2011. Ele traz reflexões sobre uma série de questões de identidade, metodologias, fronteiras e caminhos para os estudos e práticas no campo. Fazendo um paralelo com outras disciplinas que passaram pelo mesmo processo, a conclusão é que o campo da Comunicação precisa mais preservar a riqueza de sua interdisciplinaridade do que buscar respostas em uma aparente e, às vezes, falsa autonomia científica.

Palavras chave: Comunicação. Interdisciplinaridade. Campo científico. Autonomia.

\section{Communication as a Social Science (and more)}

\begin{abstract}
Communication is the most important field for the study of many key dimensions of social change. This is the basic premise of this text presented at the opening of the annual conference of International Communication Association in 2011. The subject brings a lot of reflections about a series of issues on identity, methodologies, borders and paths for studies and practices in the field. Making a parallel with other disciplines that have gone through the same process, the conclusion is that the field of Communication longer needs to preserve the
\end{abstract}

\footnotetext{
* Tradução de Edgard Rebouças. Ver nota no fim do artigo.

** Professor doutor nos departamentos de Sociologia, História, Cultura e Comunicação (Comunication Media, School of Continuing and Professional Studies) da Universidade de New York, Nova Iorque, Estados Unidos. Autor de livros, entre os quais Sociology (1989), traduzido em espanhol, alemão, mandarim e sueco; Nationalism (1997), traduzido em sete línguas; The Sage Handbook of Sociology (2005) e, mais recentemente, The Roots of Radicalism: tradition, the public sphere and early 19th (2011). Presidente do Conselho de Pesquisa em Ciências Sociais dos Estados Unidos desde 1999. E-mail: calhoun@ssrc.org.
} 
richness of its interdisciplinary than to search for answers in an apparent, and sometimes false, scientific autonomy.

Key words: Communication. Interdisciplinary. Scientific Field. Autonomy.

\section{La comunicación como una ciencia social (y más) Resumen}

La Comunicación es el campo más importante para el estudio de muchos aspectos fundamentales del cambio social. Esta es la premisa básica de este trabajo presentado en la apertura del congreso anual de la International Communication Association, en 2011. Él trae una serie de reflexiones sobre las cuestiones de identidad, las metodologías, las fronteras y caminos para el estudio y la práctica en el campo. Haciendo un paralelismo con otras disciplinas que han pasado por el mismo proceso, la conclusión es que el campo de la comunicación ya la necesidad de preservar la riqueza de su interdisciplinario de buscar respuestas en una autonomía científica aparente y falsa a veces.

Palabras clave: Comunicación. La interdisciplinariedad. Campo científico. Autonomía.

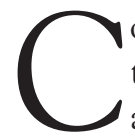

omo em geral acontece, enviei o título desta palestra antes que eu soubesse o que iria falar. Eu quero falar sobre a pesquisa em Comunicação como um campo, mas não apenas como um campo das Ciências Sociais. Tentar restringir a Comunicação no que na verdade existe hoje nas Ciências Sociais seria reduzi-la de maneira infeliz. Mas, ao mesmo tempo, como alguém muito envolvido nas Ciências Sociais, tenho a esperança de que a pesquisa em Comunicação seja aberta e profundamente integrada nas Ciências Sociais de forma mais ampla. Eu acredito que o estudo intelectualmente sério de Comunicação deve ser transformador para as Ciências Sociais.

Preparando-me para esta conferência, eu pensei que deveria descobrir o que o campo da pesquisa em Comunicação realmente é. Tinha alguns pré-conceitos e pensei ter aprendido alguma coisa com a experiência. Tenho feito pesquisas sobre temas de destaque no campo das Comunicações. Tenho participado de várias bancas de doutorado e até mesmo feito certa "cortesia" opinando na seleção de professores do Departamento de Mídia, Cultura e Comunicação da Universidade de Nova York. Fui reitor e diretor de duas importantes universidades nas quais a pesquisa em Comunicação ocupa lugar de destaque, e presidente do Conselho 
de Pesquisa em Ciências Sociais (SSRC). De fato, ao longo de meu mandato no SSRC lançamos dois programas no campo da Comunicação: um, reunindo arte e mídia, tratando de direitos de propriedade intelectual, reforma da mídia e esfera pública; e outro, em um esforço para incrementar as relações entre pesquisadores acadêmicos e ativistas. Então, eu acho que não chego a ser um completo ignorante nessa área.

No entanto, eu não estava tão confiante na minha compreensão do que mantém alinhavado o campo da Comunicação como um todo, quais suas fronteiras, seu centro gravitacional e o que o destaca tanto. Então, naturalmente, fiz o que meus estudantes de graduação fazem, e o que, se formos honestos, todos nós fazemos. Dei uma olhada no Wikipédia. E ali eu aprendi o seguinte:

Comunicação, como uma disciplina acadêmica, às vezes chamada de "comunicologia", refere-se a todas as formas como nos comunicamos, por isso abrange uma grande área de estudo e conhecimento. A disciplina de Comunicação inclui tanto mensagens verbais como não-verbais. A área da Comunicação é apresentada e explicada em livros didáticos, publicações eletrônicas e revistas acadêmicas. Nas revistas, os pesquisadores relatam os resultados de estudos que são a base para uma compreensão cada vez maior de como todos nos comunicamos.

Comunicação acontece em muitos níveis (mesmo para uma única ação), de muitas maneiras diferentes, e para a maioria dos seres, bem como em determinadas máquinas. Várias, senão todas, áreas de estudo dedicam uma parte da atenção à comunicação, por isso, quando se fala sobre comunicação é muito importante ter certeza sobre quais aspectos da comunicação se está falando. Algumas definições do alcance da comunicação reconhecem amplamente que os animais podem se comunicar uns com os outros, assim como os seres humanos, e alguns são mais específicos, apenas incluindo os seres humanos dentro dos diferentes parâmetros da interação simbólica humana. ${ }^{1}$

Deixe-me resumir minha pesquisa online. Comunicação é uma disciplina acadêmica que:

1. Cobre tudo.

2. Incide especialmente sobre as distinções entre as palavras e não-palavras, as pessoas e não-pessoas.

3. Produz livros didáticos, publicações eletrônicas e revistas especializadas.

4. É um campo completamente incapaz de gerar um bom verbete sobre si mesmo na Wikipédia.

${ }^{1}$ http://en.wikipedia.org/wiki/communication 
Felizmente, como dizemos a nossos alunos, a Wikipédia não é tudo. Pesquisa científica de verdade exige garimpo em muitos sites. Eu quero assegurar de antemão que eu vou usar agora uma base empírica totalmente adequada, já que de outro modo poderia parecer que eu faria aqui uma série de generalizações sem fundamento. Nesta base empírica proponho apresentar uma análise do campo e seus dilemas contemporâneos, e ainda dar alguns conselhos e advertências.

\section{Como um campo de estudo - em ensino ou em pesquisa - a Comunicação é realmente descontroladamente heterogênea}

A Comunicação é o campo mais importante para o estudo de muitas dimensões chave das mudanças sociais. A crescente influência da internet e das novas mídias é o mais óbvio, mas não o único exemplo. E podemos pensar nisso não apenas de forma abstrata ou em estudos sobre usos individuais, mas também em uma série de importantes contextos que vão da primavera árabe, passando pela crise financeira global, às disputas sobre a propriedade intelectual. Ao mesmo tempo, há uma centena de linhas de pesquisa mais antigas que ainda estão ativas e são muito importantes.

Esta é uma boa notícia, na maioria dos casos, já que é uma das principais fontes da vitalidade e da criatividade do campo. Mas o campo ainda não desenvolveu maneiras fortes o suficiente para integrar e se beneficiar dessa sua diversidade.

Fiquemos nas boas notícias. Não é apenas o fato que os pesquisadores em Comunicação estudam um monte de diferentes problemáticas e objetos empíricos, com um monte de abordagens diferentes, e em um monte de lugares diferentes. Mas tão importante quanto; muitos desses estudos são feitos de novas maneiras precisamente porque olham para eles a partir da perspectiva da Comunicação como um campo. Todos são estimulados a fazer novas perguntas, e se permitem romper com as abordagens que têm sido padrão em outros campos. Isto é verdade para o estudo da comunicação política - muito empolgado tanto pelos estudos culturais como pelo foco da mídia em si, ainda mais diante de um desenvolvimento lento das Ciências Políticas. É verdade também 
para o estudo da retórica, motivado pela atenção à retórica visual e para o papel do discurso desmembrado em várias mídias. Como é verdade para o estudo da música popular, repensado para além de Musicologia como uma questão de instituições culturais e múltiplos níveis de comunicação.

No entanto, como um campo, a Comunicação reflete fortemente sua gênese. A trajetória do desenvolvimento e a integração incompleta são evidentes nos subgrupos que lhe são vinculados e nas divisões internas de muitos departamentos - muitas vezes com fracas ligações entre suas linhas de pesquisa, que poderiam ser relevantes para si mesmos e para problemas mais amplos e importantes. A Comunicação foi feita a partir de (no mínimo):

a. Retórica e discurso

b. Teatro e estudos de apresentações

c. Comunicação de massa

d. Pesquisa de opinião pública

e. Comunicação interpessoal e de pequenos grupos

f. Comunicação organizacional

g. Jornalismo

h. Relações Públicas

i. Marketing

j. Análise de políticas

k. Estudos culturais

1. Meios de comunicação, o que significa:

1. História da mídia do discurso por meio da escrita, da impressão, e de uma gama de meios eletrônicos

2. Rádio e televisão

3. Cinema e vídeo

4. Novos meios de comunicação, incluindo a internet

5. Produção

6. Crítica

Eu poderia fazer essa lista ainda maior, não menos importante, enfatizando mais as disciplinas a partir das quais alguns imigrantes vêm para a Comunicação, como: Literatura, História, Sociologia, entre outras. Alguém que conhece o campo melhor 
do que eu poderia fazer uma discussão sobre qual dessas muitas dimensões são mais importantes. Meu próprio senso é que a mídia é a mais marcante, mas que os estudos mais criativos de mídia não se sustentam sozinhos, eles conectam a mídia com outras questões, tais como: as mudanças culturais, a desigualdade social, a estrutura organizacional.

Notem, também, o que está faltando. Há campos que poderiam ser muito melhor representados em estudos de Comunicação do que são agora, como por exemplo:

m. Política, economia e economia política

n. Engenharia e ciência da computação

o. Design

Seria de se imaginar que todos os programas e cursos de Comunicação devessem, de alguma forma, "cobrir" todos estes subcampos e temas com suas linhas de estudos (deixem de lado aqueles que têm a pretensão de ter uma casa exclusiva). A questão não é de criar um guarda-chuva ou de um empacotamento, é de ter conexões. Vale a pena para o campo como um todo refletir sobre o desafio de integrar e conectar essas diversas fontes e focos.

A Comunicação é heterogênea não apenas na mistura de campos que incorpora, mas nos modelos organizacionais e curriculares que produziu por si mesma. Há cursos em que produção é fundamental, e aqueles que são mais de análise. Existem programas de Comunicação que enfatizam a formação profissional e, na verdade, alguns que são organizados como escolas profissionais. Em alguns dos cursos, o Jornalismo é central; em outros não. Em algumas universidades, há uma harmoniosa integração entre os departamentos (ou pelo menos na medida do possível). Em outros, as tensões geram frequentemente lacerações entre os colegas, e em outros ainda buscando o caminho de um mundo mais racional - existem vários departamentos buscando versões diferentes de comunicações. Meu objetivo não é o de enaltecer o conformismo, mas sim indicar um desafio. E não faço sem base material e implicações.

A diversidade e o caos criativo do campo da Comunicação se tornam preocupantes em vários pontos específicos. Por exemplo: 
- Quando se explica aos pais dos alunos porque o curso de Comunicação é bom para eles.

- Quando se pede às administrações centrais para contratar novos docentes.

- Quando perguntam por que os financiadores importantes, como a National Science Foundation (NSF), tratam a pesquisa em Comunicação como marginais, na melhor das hipóteses.

- Quando analisam estágios probatórios de professores.

- Quando criam ou debatem a estrutura curricular.

Tudo isso realmente importa, mas importa principalmente de forma prática, e não deve ser feito por questões de princípios. Não possuem quaisquer implicações muito claras sobre o mérito intelectual ou a coerência do campo. Em outras palavras, não me sinto mal sobre isso. Não é como qualquer um que tem a sua casa disciplinar em ordem. Cada campo é heterogêneo: a questão é o quão bem suas partes são conectadas.

\section{A importância e os limites da disciplina}

Na verdade, as disciplinas "estabelecidas" não são tão antigas e também variam muito em suas organizações internas. A maioria delas assumiu sua forma moderna há apenas cerca de 100 anos, na esteira do aumento dos cursos de doutorado e em meio à tentativa de redefinir a universidade moderna como uma instituição que integra ensino e pesquisa. Isso transformou o antigo modelo de disciplinas e campos de estudo, que ainda eram baseados no clássico - mas também profissional - projeto de formação de padres. $\mathrm{O}$ modelo antigo era interdisciplinar, por assim dizer, porque supunha que os alunos estudariam todos os assuntos principais em uma só formação. Além disso, os professores poderiam se movimentar por meio de uma hierarquia de cadeiras (cátedras) como Filosofia, Retórica ou Teologia, sem precisarem se especializar permanentemente em nenhuma delas como um campo separado. A ideia das atividades liberais ganhou um novo significado quando o velho modelo acadêmico foi der- 
rubado. Nos Estados Unidos, em particular, foi constituído um modelo que integrava campos disciplinares de pouco a pouco. O que teve seu grande início com as "optativas livres", isto é, a opção de estudar assuntos específicos fora do currículo clássico, o que favoreceu o crescimento de novos campos de concentração. A maioria deles foi criada a partir dos novos programas de doutorado. Esses campos de pesquisa acabaram se transformando nas principais disciplinas. Eles foram agrupados nas divisões de Ciências, Ciências Sociais e Humanidades, mas fizeram da universidade como um todo um espaço interdisciplinar. ${ }^{2}$

No mundo científico, há redefinições constantes de campos. Onde estão as fronteiras claras entre a Física e a Astronomia, ou das Ciências Atmosféricas? Botânica e Zoologia antes eram vistas como distintas, e se fundiram em Biologia. A Biologia, por sua vez, cresceu para contemplar vários subcampos perdidos em torno da idéia de evolução. Alguns desses subcampos, como a Genética ou a Biologia Molecular, tornaram-se tão grandes (em número de pesquisadores ou em orçamentos) como as disciplinas das Ciências Sociais. Campos interdisciplinares como a Bioquímica e a Nanotecnologia estão em constante formação e reformulação. Tais processos nunca ocorreram sem atritos, embora tenham sido ajudados pela ideia de que a ciência é em si uma atividade compartilhada, bem como mantida por fluxos substanciais de financiamento de pesquisa. Essa é uma questão em aberto, em outras palavras, saber se a Biologia é "uma" disciplina ou se é um campo interdisciplinar.

\footnotetext{
2 Por outro lado, tanto a ideia de um fundamento em "educação geral”, como a noção de conteúdos compartimentados, reflete certa continuação do antigo ideal curricular de cobrir todos os campos. Esse prolongamento afeta tanto alunos pressionados por formações direcionadas para trabalhos específicos, como algumas áreas de pesquisa, especialmente em ciência e tecnologia; já que há o argumento de que os estudantes não podem simplesmente correr com seus cursos. Isso tem atingido gradualmente o compromisso entre a amplitude e a profundidade, que há muito tempo caracteriza a estrutura da graduação nos Estados Unidos. A mudança é mais acentuada fora das escolas de ponta voltadas para profissões liberais. Há casos de cursos de Comunicação que retomam de forma interessante alguns elementos do modelo das formações liberais com um enquadramento parcialmente profissionalizante.
} 
Por outro lado, o enquadramento disciplinar para as Ciências Sociais foi mais ou menos estabelecido no início do século 20. Economia, Sociologia e Ciências Políticas brotaram todas de um recorte do campo da História entre as décadas de 1870 e 1910 sendo que a Sociologia foi inicialmente organizada mais no interior da Economia, até que foi criada sua própria associação científica em 1905. A Psicologia seguiu seu próprio caminho de desenvolvimento, foi fortemente vinculada com as Ciências Sociais até o final do século 20, mas agora tem fortes ligações com as Ciências Naturais na maioria das pesquisas acadêmicas. A Antropologia e a Geografia também nasceram da divisão que deu origem às Ciências Sociais. Este é um dos motivos pelo qual os antropólogos se sentem tão desconfortáveis ao trabalhar nos departamentos de Sociologia. E continua havendo um racha na Antropologia; basta ver os argumentos levantados no ano passado, quando a Associação Americana de Antropologia propôs retirar a palavra "ciência" de seus documentos oficiais. O domínio da Geografia Física mostra que a maioria dos departamentos de Geografia nos Estados Unidos foca seus estudos mais nas Ciências Naturais do que nas Sociais, deixando de lado a Geografia Humana, ao menos no mundo anglófono.

Cada uma das disciplinas emergentes das Ciências Sociais é composta por subcampos com potencial para se tornarem disciplinas separadas por conta própria (o que também significa que há algo de interdisciplinar dentro de cada um deles). Apesar de sempre ter sido bem financiada, ser importante para as políticas públicas, e ter uma forte tradição de pesquisa e associações profissionais, a Demografia nunca conseguiu ganhar autonomia disciplinar na maioria das universidades. Mesmo com sua vigorosa refundação após a Segunda Guerra Mundial, as Relações Internacionais nunca conseguiram se separar das Ciências Políticas (exceto nos lugares em que se mudou para as novas escolas de Comércio Exterior). Nem mesmo os esforços para criar uma unidade maior entre certas áreas conseguiu derrubar disciplinas já estabelecidas, como no caso do famoso e influente Departamento de Relações Sociais de Harvard.

Seria interessante explorar um pouco mais o motivo pelo qual as disciplinas das Ciências Sociais são tão resistentes a qualquer reorganização (embora este não seja o lugar para uma investigação 
aprofundada). Pelo menos nos primeiros anos, algo disso tinha a ver com tendências políticas: História e Ciências Políticas eram relativamente conservadoras, enquanto Economia e Sociologia eram mais liberais, voltadas para o ativismo social, e às vezes até socialista. Sem dúvida, algumas das respostas têm a ver com o fato de que todas se sentiam ameaçadas e queriam proteger sua legitimidade (uma questão que pesou muito, por exemplo, foi o fato de alguns sociólogos como Paul Lazarsfeld e Robert Merton - que também contribuíram de forma importante para a Comunicação terem mantido o campo no limite do comprimento de seus braços).

Por algum motivo, nenhuma das outras Ciências Sociais abraçou a pesquisa em Comunicação de todo coração. Entre as várias áreas das Ciências Sociais, nenhum espaço foi ainda criado para a Comunicação como uma disciplina independente. Nem mesmo os programas mais antigos de Comunicação como Discurso, enraizados nas Ciências Humanas, acolheram plenamente o crescimento da pesquisa Comunicação nas Ciências Sociais. Mais do que qualquer outra coisa, foi o crescimento dos cursos profissionalizantes no pós-guerra, principalmente a partir da década de 1970, que fez com que houvesse um aumento impressionante de departamentos de Comunicação.

Disciplinas mais antigas mostram ser extremamente lentas para reverem suas problemáticas e se organizarem internamente para assumirem novas questões sobre comunicação e mudanças sociais. Mas isso deve servir como um aviso sobre as aspirações excessivas para "ser uma disciplina como as outras". A disciplina que se enrijece geralmente oferece provas intelectualmente conservadoras. Orientadores aconselham a seus estudantes de pós-graduação que é melhor escrever dissertações sobre temas bem estabelecidos, em subcampos bem estabelecidos. E cuidado! Isso já está acontecendo na pesquisa em Comunicação. Não é o caso de o campo ser livre por natureza; mas sim que é relativamente novo, que cresce rapidamente e que tem uma fraca institucionalização. Estes são elementos que incentivam a liberdade, mas podem ser apenas temporários.

Resumindo, a Comunicação não precisa ter tanta ansiedade ao invejar uma disciplina. Todas as disciplinas e todos os campos 
profissionais têm mais ou menos demarcações arbitrárias intelectualmente. Eles têm histórias que os marcam como uma "assemblage". Este é um termo atualmente em moda, que muitas vezes é usado como se significasse algo mais profundamente teórico; mas que eu acho que na verdade significa que o que é fruto de uma colagem não tem como ser automaticamente coerente, não é facilmente teorizável, e exige muito trabalho para sua manutenção. Assim é com a Comunicação (e com muitas outras disciplinas das Ciências Sociais): na procura pelo princípio unificador é provável que encontre algo que seja enganoso ou contraproducente. A unidade é mais uma questão de conexões e de semelhanças familiares. Claro, isso não impede as pessoas de fazerem alegações tendenciosas sobre a integridade de princípios das disciplinas mais antigas.

Permitam-me uma anedota: quando eu fui reitor na Chapel Hill, o Comitê Curricular de Artes e Ciências estava debatendo sobre a importância da inclusão de uma linha de Estudos Culturais para ser alojada no Departamento de Comunicação. Uma historiadora se opôs com toda força: "Como os Estudos Culturais podem ser uma linha, se não são fundamentados em uma única característica metodológica, como é próprio de qualquer disciplina?". Como um defensor crítico e reflexivo das Ciências Sociais, não pude deixar de perguntar de volta: "E qual é a metodologia única que unifica a disciplina de História?”. "Uhhh”, ela gaguejou, "bem, o passado; os documentos, quero dizer, os arquivos". Acho que vocês concordam comigo que nem todos os historiadores trabalham com arquivos, ou com documentos, e, além disso, por que tudo aquilo que o passado possa ser, um método é que não é. Nem a História tem um método único que a defina (embora alguns historiadores tenham fortes afinidades de estilo e gosto). ${ }^{3}$

\footnotetext{
${ }^{3}$ Uma atualização: $O$ programa interdisciplinar dos Estudos Culturais continua próspero em Chapel Hill (rebatizada como Cultural Studies@ UNC). No entanto, quando o Programa de Pós-Graduação recentemente postou sua lista de cursos, pode-se ver ali Estudos Asiáticos, Estudos da Mulher, Estudos Religiosos, Pesquisa Afro-Americana, Minorias Idosas, e até mesmo o Estudos Sul-Americanos. Sendo um programa que não oferece na verdade uma linha Estudos Culturais. Evidentemente, "estudos culturais" ganharam outra vida como uma área de promoção da diversidade ou o estudo das culturas minoritárias.
} 
A ideia de que poderia haver uma metodologia comum para pesquisa em Comunicação é risível. Mas é importante também rir da ideia que há um único método comum para a Antropologia, a Economia, a História, a Psicologia, as Ciências Políticas ou para a Sociologia.

Essa noção de que métodos definem disciplinas é uma ilusão com raízes no final do século 19, quando ocorreu uma tendenciosa divisão entre as ciências puramente objetivas e generalistas e aquelas que embasavam seu conhecimento a partir de subjetividades, dando ênfase à interpretação. $\mathrm{O}$ methodenstreit não teve nenhum sucesso intelectual e não é assim que as disciplinas são realmente organizadas. Claro que isso não impediu os cientistas sociais de continuarem tentando reivindicar uma posição mais científica ao insistirem que seus métodos são cada vez mais aperfeiçoados para a objetividade. Também não parou as recorrentes movimentações para se substituir um conjunto de métodos por outro, nem as afirmações de que determinadas técnicas constituem um perfeito padrão para a busca do conhecimento - os grandes trunfos são afirmarem os experimentos duplamente cegos e os levantamentos com a análise completa da população, em vez de em amostras.

Pesquisadores das ciências naturais e físicas geralmente alegam o método científico como fundamento comum de todos os campos científicos (e, neste sentido, o método científico não se identifica com uma técnica de pesquisa em particular). Esta é a razão de se falar ciência no singular, enquanto que em frases onde se usa "artes e ciência" as várias artes são vistas como algo incomensuravelmente plural. As humanidades têm sido tratadas dessa última forma (o que talvez faz mais sentido para as Artes, como pintura, escultura e poesia). Pesquisadores das Ciências Humanas normalmente afirmam que cada disciplina deve ser definida por um método específico. Isso nem sempre funciona no transcorrer de uma pesquisa ou em uma parceria interdisciplinar, mas é quase sempre enganador nas aparências. São os cientistas sociais, no entanto, os mais propensos a fetichizar o método como técnica, e buscam status científico nesse fundamento. A Comunicação é um dos campos menos provável para ser definido por um método comum. Há grande diversidade de métodos de se comunicar, 
da fala à escrita, ao cinema, ao rádio e a televisão, e assim por diante. E há uma grande diversidade de métodos para se estudar a Comunicação, com contribuições de experimentos, etnografias, pesquisas históricas, levantamentos, análises textuais e métodos cada vez mais visuais. Mas há também uma perene renovação do methodenstreit. A pesquisa em Comunicação continua dividida entre o abraço do universalismo científico e o foco humanístico nos contextos e nos casos, entre a busca da precisão quantitativa e da profundidade interpretativa. Meu conselho aqui é simples, vindo do igualmente dividido campo da Sociologia: superem isso. Nenhum dos lados é detentor de toda a verdade.

Isto não quer dizer que não haja questões interessantes para explorar a respeito do método. Em primeiro lugar, é claro, sempre há a possibilidade de se melhorar técnicas de pesquisa (embora técnica tenha um sentido mais limitado que método). Segundo, existem questões importantes sobre o que conta como um bom conhecimento e porquê, e estas precisam de explorações reflexivas - mas no espírito da melhoria do conhecimento não há nenhuma busca que tenha um fim. Nesse sentido, podemos considerar a História, que não tem um método único, mas tem um subcampo de Historiografia que faz perguntas fundamentais sobre como podemos conhecer o passado e como podemos usar os diferentes métodos (e conceitos e teorias). Em terceiro lugar, há questões vitais sobre quais competências uma pós-graduação de Comunicação deva possuir. Se pensamos em estudar Comunicação como a possibilidade de dominar uma série de habilidades, quais seriam elas? Quantas linhas deveriam ser unicamente para as comunicações, e quantas seriam compartilhadas com outros campos? Seria possível usar alguma teoria para se analisar o que estaria na linha? Haveria estatísticas? E nesse caso, sendo que estamos falando em comunicação, isso seria falado ou escrito de forma clara para compreensão do público em geral, como seria de se supor?

Há questões em todas as Ciências Sociais (e de fato em todos os campos) sobre a relação entre padrões curriculares e pesquisa de ponta. Há boas razões tanto para ensinar aos alunos habilidades básicas já estabelecidas, como para ensinar os conhecimentos que 
vêm ganhando aceitação, onde se debate novas questões que estão mudando a forma como pensar o campo.

Não são apenas os pesquisadores em Comunicação que abordam estas questões de maneira confusa e ansiosa, já que não há apenas uma resposta certa e não há respostas possíveis que não sejam passíveis de julgamentos sobre o valor intrínseco das diferentes possibilidades de trabalho.

Nada disso significa que insistir em rigor seja um equívoco, só que este rigor vem de várias formas. Nem significa que o campo da Comunicação não se beneficie de uma forte narrativa coletiva, só que essa narrativa tem que ser aquela que contempla a diversidade, e não aquela que tenta disciplina-la. Mas contemplar a diversidade significa criar conexões mútuas, não apenas tolerância.

Em outras palavras, decanos e chefes de departamento não devem tomar essa relativa desordem intelectual como uma oportunidade para lançarem esquemas tendenciosos em busca de coerência. Ao mesmo tempo, o resto do corpo docente deve ver a importância dos esforços dos dirigentes para representar o campo para seu público externo e não tentar minar tal ação sempre que tiverem oportunidade. Representações do campo são importantes não só para auxiliar pessoas de fora - inclusive financiadores e verem seu valor. É útil para os alunos. E é útil para todos os membros do campo - não apenas para que eles tenham algum credo para recitar, mas para que tenham um foco para refletir sobre preocupações comuns. Se é o trabalho dos dirigentes falar com os reitores e com os doadores para se alcançar alguma clareza, é o trabalho dos pesquisadores debater ambiguidades e levantar questões para futuras pesquisas. Mas o campo não pode prosperar se quiser somente conquistas sobre outros.

Este não é um problema apenas para a academia. É importante que as tentativas para representar e integrar o campo da Comunicação incluam profissionais que trabalhem fora das instituições de ensino e pesquisa. É necessário apoiar o engajamento público de pesquisadores e de profissionais da mesma forma. Tanto o trabalho profissional como o engajamento público depende da oferta de conhecimento, o que merece respeito. Tal conhecimento significa fundamentalmente (a) a pesquisa e (b) os questionamentos críticos 
que os campos de pesquisa trazem à tona de que isso ou aquilo seja uma verdade estabelecida. Diversidade não deve significar tolerância ao trabalho desleixado, nem a coerência deve ser alcançada reprimindo a criatividade.

\section{Como o campo da Comunicação pode ganhar forma e coerência?}

Os temas estudados pelos pesquisadores em Comunicação são extraordinariamente diversificados. Eles variam de possibilidades extremamente micro como o uso de telefones celulares a outras extremamente macro como os fluxos e influências das informações globais. Isso é muitas vezes visto como um problema, como se o campo devesse superar a diversidade temática e definir sua atenção a objetos mais específicos. Mas eu acho que isso é ilusório.

Deixem-me dar exemplos de três campos que têm desfrutado de grande vitalidade intelectual, crescimento e influência nos últimos 35 anos ou mais. A Economia é frequentemente criticada (principalmente por não-economistas) por ter uma abordagem de análise excessivamente padronizada e fronteiras muito bem estabelecidas. Ela é vista como obcecada pela matematização e autista em sua auto-referencialidade. Mas dificilmente pode ser acusada de falta de diversidade temática. Como os economistas passaram a usar suas ferramentas para uma gama cada vez maior de objetos de análise - do casamento e da vida familiar a doenças infecciosas -, se arriscaram e pagaram um alto preço por tal comportamento. É claro que a problemática dos economistas continua distorcida. Porque os economistas adquiriram prestígio, em grande parte, pela implantação de certos tipos de ferramentas de uma forma elegante e original, problemas que não se adequam bem a essas ferramentas tendem a ser negligenciados. Mas, apesar de podermos dizer que a Economia seja um exemplo de uma disciplina que se tornou muito disciplinada, e poderíamos reclamar da excessiva dependência de noções como mercados eficientes e atores representativos, o que ocorreu foi uma amplitude de pensamentos e a abertura a diferentes tipos de análises, não uma diversidade temática.

Da mesma forma, ocorreu a transformação nas escolas de Negócios na última grande recessão acadêmica, durante a década 
de 1970. Elas têm crescido enormemente, não apenas em número, mas também em status e em influência. Nesse processo, elas saíram do papel de relativa superficialidade intelectual - e baixo status na hierarquia universitária - para se tornarem centros de pesquisa e, muitas vezes, líderes em uma pedagogia eficaz. Tais escolas fizeram isso englobando um conjunto de abordagens ou disciplinas analíticas, tornando-se o principal lar dos financiamentos, a partir do qual o pensamento econômico dominante passou a ter um relacionamento próximo, em parte porque trabalhavam com estudos aplicados, mas também pela atenção ao marketing, ao comportamento organizacional e à contabilidade. Alguém poderia questionar até que ponto existe uma base intelectual comum a esses vários campos. Se isso estiver claro, pelo menos ideologicamente, nos MBAs, há duas ideologias: estudos de caso e análise técnica. Mas não há falta de diversidade temática. Como a abordagem dos Negócios têm sido exercidas sobre quase todas as áreas da vida social, há tanto perspectivas analíticas e como há abordagens para lidar com questões práticas. Quantos de vocês não têm sido questionados sobre o modelo de negócio no qual suas universidades ou departamentos estão inseridos?

E por último, mas não no final, acho que a Biologia tem sido provavelmente o campo mais dinâmico e produtivo intelectualmente dos últimos 35 anos. Ela tem sido o local das principais revoluções intelectuais, como a ênfase dos estudos sobre o genoma e seu papel central em projetos como a neurociência. Tais abordagens têm moldado as reconfigurações de como os biólogos trabalham e suas relações com outras disciplinas. Por exemplo, a pesquisa genética gerou um campo híbrido de biologia computacional que não apenas trouxe cientistas de Computação e programadores para os programas de Biologia, mas também mudou a velha divisão primária entre biólogos de campo e pesquisadores de laboratório.

A Biologia foi remodelada por novos métodos, perspectivas analíticas e teorias. Sua coerência foi testada como passou por constantes reestruturações, desde a combinação da Botânica com a Zoologia, passando por sua separação parcial das Ciências Agrícolas, pela diversificação das linhas de pesquisa médica e farmacêutica aplicada, chegando à ascensão de áreas bem interdisciplinares, 
como a nanotecnologia. Houve uma série de pressões para unificar a Biologia; através da teoria evolutiva, através da pesquisa molecular, e até do incremento da computação e dos estudos sobre o genoma. Mas mesmo passando por tudo isso, a diversidade de objetos empíricos era grande e continuava aumentando. O que foi melhor compreendido, não foram apenas as inúmeras novas espécies identificadas, mas também a complexidade interna dos organismos e sua interação uns com os outros, assim como diversos fenômenos físicos. E, como deve ser no caso da Comunicação, a Biologia transcendeu a postura de observação puramente objetivista para assumir uma posição sobre a reconstrução dos fenômenos observados. A Biotecnologia não é apenas uma aplicação da Biologia; ela mudou a Biologia e criou fenômenos biotecnológicos híbridos que entraram em novas interações com organismos, ambientes, e uns com os outros.

Baseado nesses três exemplos, eu não acho que a diversidade de objetos empíricos seja um problema para o campo da Comunicação. Na verdade, pode ser até uma virtude. Mas para que ela seja mesmo uma virtude, a diversidade de temas deve ser interligada por meio de uma teia de interconexões. $\mathrm{O}$ mesmo vale para a variedade de métodos, a multiplicidade de orientações para a prática profissional, a difusão do conhecimento e o desenvolvimento acadêmico. Não há um modelo único para isso: a Economia, os Negócios e a Biologia sugerem diferentes caminhos potencialmente bem sucedidos. Mas nisso a Comunicação enfrenta um desafio. Ela tem fracas conexões entre suas linhas de pesquisa, e até certo ponto, entre os próprios pesquisadores. Isso é em parte devido ao elevado índice de imigração para o campo, sobretudo de pesquisadores que mantêm fortes relações com outros campos ou disciplinas onde se formaram. Mas não é só isso. É também uma questão de haver muitas - e as vezes concorrentes - associações profissionais e científicas, e do contínuo fortalecimento dos vários campos mais antigos, que servem de afluentes para o rio da Comunicação. É um problema para se perguntar, até que ponto os pesquisadores que trabalham com questões da Comunicação em diferentes níveis de análise ignoram o trabalho dos outros, como se não houvesse nenhuma razão para se imaginar que a economia 
política ou a cultura influenciariam - ou seriam influenciadas pela comunicação interpessoal e organizacional.

Um último ponto a ser sugerido, é o que observar a relativa fragilidade da integração das discussões teóricas. Não quero dizer que a Comunicação deva aspirar a um tipo de compartilhamento teórico que se impôs na teoria neoclássica na Economia, que gera até alguns compromissos cegos. Compartilhar argumentos pode ser tão valioso quanto compartilhar acordos. Mas estamos em um momento em que a teorialite é a norma nos estudos da Comunicação - como em boa parte das demais ciências humanas e sociais. Isto pode ser em parte uma resposta previsível aos ascendentes excessivamente doutrinários (sem citar nenhum jargão camuflado) do marxismo, pós-estruturalismo, pós-modernismo, e outros projetos (especialmente aqueles com raízes francesas e alemãs) que taxou sobre a teoria marcas secretas de distinção ao invés de esclarecimento intelectual. Ajudar a integrar suas diferentes partes e linhas de investigação é um problema enfrentado por quem trabalha com teoria em qualquer campo. Esta não é só uma questão de assentar as bases ou perseguir sínteses, é também uma questão de fornecer os termos de referência para o debate crítico. A falta de integração e de reflexão crítica são problemas tanto para permitir que a pesquisa empírica tenha profundidade e acúmulo acadêmico significativo, como para permitir aos pesquisadores de dizer por que seus trabalhos realmente importam.

Este não é o lugar para se ir, mas tem um significado e importância, são juízos que podem ser feito apenas em relação a alguns problemas ou projetos. Problemas e projetos são práticas e teorias e, muitas vezes ao mesmo tempo. Estou dando destaque para o que certa vez os fenomenologistas chamaram de intencionalidade, o que Habermas chama de interesse de formação do conhecimento, e para uma abordagem pragmática para o conhecimento. Não me proponho a distinguir estas ou a acrescentar algo ao que poderia ser uma longa lista de referências. Estas três são suficientemente diversificadas para mostrar que esse tema não é específico para uma única escola de pensamento. A questão aqui é que uma das coisas mais importantes que faz com que um campo seja coerente e produtivo é o engajamento no compartilhamento de problemas 
teóricos e práticos ou de projetos. Estes não são simplesmente temas sobre os quais sabemos mais ou menos. Eles são esforços de compreensão ou ação para que nosso conhecimento não seja inútil, insuficiente ou enganoso. Por exemplo, querendo saber como uma específica mídia ou mecanismo afeta tanto o processo como o conteúdo da comunicação de uma grande variedade de projetos; podemos passar pelas pesquisas de John Durham Peters em "falando para o ar", pela exploração de Eszter Hargittai sobre o uso de motores de busca, pelas análises de James Katz a respeito do uso de telefones celulares, chegando às explorações de Larry Grossberg sobre a relação da música popular e da cultura jovem. As mesmas questões estão ligadas a ações práticas como as políticas da Comissão Federal de Comunicação (FCC) sobre a concentração da propriedade em todos os setores da mídia. Escolhi especificamente exemplos que, penso eu, aparecem em lugares muito diferentes em qualquer mapa do campo da pesquisa em Comunicação - digamos, criados a partir de co-citação padrões. Destaco que, se o campo levanta problemas, é porque tais tipos de conexões foram feitas. A disparidade e, as vezes, as grandes especificidades nos questionamentos tornam-se parte de projetos maiores que visam resolver os problemas que aparecem em diferentes configurações em escalas diferentes.

A coerência em um campo como a Comunicação não precisa ser ancorada em nenhum plano miraculoso ou em um método comum. Tal coerência deve surgir associada ao resultado de inúmeras conexões específicas entre linhas de pesquisa, subcampos, práticas profissionais e compromissos públicos sem que haja um conjunto único de regras que expliquem ou organizem todos estes pontos. É extremamente importante fazer tais conexões intelectuais, e isso é necessário para assumir grandes questões que são importantes para o trabalho de muitos subcampos.

$\mathrm{O}$ argumento apregoado de que um campo deve ser o mais amplo possível faz sentido para mim, mas eu vejo minimamente contemplado nas atuais políticas de formação, contratação ou de promoção. Na verdade, os departamentos costumam buscar novos docentes por especialização e reconhecimento de suas publicações em subcampos. Programas de doutoramento parecem, na maioria 
dos casos, adaptados a isso, forçando os estudantes a se especializarem e publicarem mais do que a debater teoricamente ou aprender sobre o campo como um todo.

Esse não é um problema apenas para os programas de doutoramento. A formação de um campo tem como principais desafios a construção de conexões e a busca por padrões interligados de pesquisa. Há algumas questões centrais sobre isso:

- Quais os valores comuns defendidos pelo campo? Em outras palavras, qual é o seu projeto, os riscos de suas disputas, seu capital simbólico específico? Seja qual for a resposta, um corolário inevitável é que tudo isso demanda avaliação. Todos os campos acadêmicos julgam o valor de suas contribuições. Disciplinas são muito influenciadas especialmente pelo esforço de manter a qualidade por meio de decisões que envolvem titulações, artigos publicados e julgamentos feitos por seus pares, de campos interdisciplinares ou profissionais. $\mathrm{O}$ valor pode ser descrito em termos da "qualidade" da pesquisa, embora isto possa ser avaliado ao longo de uma gama de variáveis, que passam pela criatividade, amplitude e até pela originalidade para conquistar um maior número de bolsas de estudos. Como o campo da Comunicação avalia a importância de suas contribuições é fundamental para estabelecer seus valores fundamentais e moldar sua identidade.

- E quem vai fazer a avaliação? Até que ponto os diferentes subcampos da pesquisa em Comunicação vão simplesmente protelar uns aos outros, adotando uma atitude de viva e deixe viver? Ou até que ponto as pessoas de um subcampo vão intervir em avaliações de outros sem primeiro se preocuparem em aprender os tipos específicos de valores que são importantes para as contribuições nessa ou naquela linha de trabalho? O que está em jogo é a questão de saber se existe uma verdadeira compreensão mútua dentro do campo, bem como os desdobramentos das diferentes opiniões individuais. 
Estar situado entre uma disciplina e um campo interdisciplinar contribui para os problemas. Por exemplo, o candidato a um concurso para professor de Comunicação deve ser avaliado por colegas da Comunicação ou de outras áreas? Faz diferença se o candidato em questão fez seu doutorado em História, ou em Sociologia, ou em Ciências Políticas, e não em Comunicação? Ou se publica majoritariamente em revistas de outras áreas? E como devemos tratar as relações assimétricas usadas por departamentos de Comunicação que contratam membros do corpo docente vindos de várias disciplinas, e que jamais considerariam a contratação de um professor com doutorado em Comunicação? Departamentos de Sociologia enviam alegremente recém-doutores para empregos, não só em departamentos de Comunicação, mas também de Estudos Étnicos, Estudos de Gênero e Estudos Internacionais, e também para escolas de Negócios e de Saúde Pública, mas raramente iriam contratar docentes com doutorados nesses campos.

Padrões mais ou menos semelhantes podem ser observados em quase todas as áreas profissionais e na maioria dos campos interdisciplinares das Humanidades e das Ciências Sociais. Em resposta a essa assimetria, no sentido em que é importante para os membros de um corpo docente não terem suas lealdades divididas, e também no sentido de que devem ter um conhecimento mais ou menos detalhado do campo em que ensinam (ao contrário de conhecer apenas uma intersecção com os outros), o padrão geral é que cada campo interdisciplinar ou profissional tenta montar a maior parte de seu corpo docente a partir de seus próprios programas de doutorado. Naturalmente, esta pode ou não ser uma boa opção.

Como um campo gerencia suas relações com outros é uma questão de limites e fronteiras. A Comunicação, como vimos, tem fronteiras extremamente tênues. Será que isso importa? É muito desejado? Em geral, uma capacidade para manter limites está intimamente relacionada com a autonomia. Mas fronteiras são também locais de trocas. Departamentos de Comunicação devem, por exemplo, assegurar recursos das universidades em que estão localizados (ou de fundações e mantenedores). Quais são os termos de negociação nessas transações? Quanto de controle os departa- 
mentos devem manter de suas próprias agendas? $\mathrm{O}$ que eles podem contribuir com outros a fim de obter recursos? Isso é reconhecido? E os departamentos de Comunicação devem desprezar os rankings ou tentar estar entre os campos que são classificados? Ou, como eu suspeito que seja frequentemente o caso, os departamentos de Comunicação são particularmente suscetíveis de serem produtores em larga escala, ao invés de produtores de excelência? Em outras palavras, eles são analisados por contribuições genéricas medidas quantitativamente, mais que por suas contribuições especificas julgadas por pares do próprio campo? Ou, sendo mais direto, eles são mais voltados a serem árvores de dinheiro dentro de suas universidades, mais valorizados por suas matrículas na graduação do que por seus programas de doutorado ou de pesquisa? E onde for esse o caso, o quanto isso prejudica a autonomia? Estas são perguntas não apenas sobre sentimentos, mas também sobre como as universidades organizam seus orçamentos.

\section{que significa ser interdisciplinar?}

O estudo da Comunicação é claramente um campo interdisciplinar, mas não está nada claro o que isso significa. Alguns pensam que a Comunicação deveria tornar-se mais de uma disciplina, apontando especialmente as preocupações com a falta de rigor ou de normas comuns. Outros prezam pela interdisciplinaridade, embora estejam divididos quanto a isso ser conseguido de uma maneira melhor: tornando-se uma escola profissionalizante, ou pela combinação de campos das atividades liberais. Comunicação não é o único campo onde tais questionamentos ocorrem; questões semelhantes surgem em Estudos Internacionais e em Estudos Ambientais.

Não vou me alongar nas virtudes da interdisciplinaridade, apesar de acreditar que elas sejam muitas, incluindo a de ser mais "divertida". Mas é importante ver que isso também pode ser um desafio. Meu amigo Ernest Wilson, diretor da Escola Annenberg de Comunicação e Jornalismo da Universidade do Sudeste da Califórnia, gosta tanto de interdisciplinaridade que deu-lhe um nome de animal de estimação, a sigla "ID". Eu sou da mesma opinião e concordo que a interdisciplinaridade é vital, mas é tam- 
bém importante diferenciar ID de $\mathrm{ADD}^{4}$. A interdisciplinaridade não é apenas uma disciplina resistente, da forma como minha geração tratava a resistência à autoridade. Há várias boas razões para ser interdisciplinar, mas todas dependem da manutenção de uma certa disciplina.

Na verdade, o Conselho de Pesquisa em Ciências Sociais (SSRC) foi fundado em 1923 com apenas estas questões em mente. Os fundadores eram professores de Chicago e de Columbia - duas universidades que lideravam na formação de doutores e nas inovações curriculares. Eles receberam o apoio da família Rockefeller para seus projetos em avançar o trabalho em "interdisciplinas" (inventando assim o projeto de interdisciplinaridade). Suas argumentações eram de que, deixados por conta própria, os gênios acadêmicos falariam apenas uns com os outros e com linguagem muito específica. Isso era um problema, eles pensaram, porque atrapalhavam os avanços no método entre disciplinas, e porque problemas do mundo real não eram organizados por disciplinas, mas sim por uma perspectiva mais ampla, que exigiam uma colaboração interdisciplinar.

Oferecer várias perspectivas para atuar sobre problemas do mundo real acabou sendo não só um objetivo digno, mas também um mecanismo eficaz. Parcerias interdisciplinares aumentaram e colaboraram para a compreensão e o entendimento de trabalhos uns dos outros em problemas comuns, mais do que quando simplesmente discutiram em suas diferentes áreas.

Mas os fundadores do Conselho de Pesquisa em Ciências Sociais (SSRC) também reconheceram que era importante refletir com base em altos padrões de qualidade. Parte da agenda interdisciplinar teve que ser melhorada qualitativamente. Isso significava melhorar a pesquisa empírica, e o Conselho foi fundamental para aprimorar as técnicas de pesquisa empírica e para o aprofundamento de questões metodológicas. Estes foram precisamente os projetos interdisciplinares, como, por exemplo, melhorias na pesquisa de levantamento, nos modelos matemáticos e no uso de computadores, o que beneficiou muitos campos científicos (e permitiu que os vários tipos de cientistas sociais usassem a pesquisa

\footnotetext{
${ }^{4}$ Sigla em inglês para Distúrbio de Déficit de Atenção (N.T.)
} 
para acompanhar preocupações públicas). Melhorar a qualidade significava também ter certeza de que teoria e pesquisa em diferentes campos dialogavam bem com outros, e o Conselho foi ativo na exploração de conceitos e agendas de difusão científica, bem como no avanço de quadros teóricos. Isso foi tão importante para reunir pesquisadores de diferentes disciplinas em contextos específicos, como grupos de estudos da área como era em projetos generalizantes, como para a pesquisa comparativa e a modelagem matemática. E cada abordagem tinha a ver com a garantia de rigor intelectual, embora de maneiras diferentes.

O outro importante argumento para a interdisciplinaridade é que ela ajuda a promover a inovação. Isto tem sido discutido com base em numerosos estudos de investigação científica. Devo acrescentar que isso está de acordo com uma das conclusões centrais da pesquisa em Ecologia: fronteiras, zonas onde os ecossistemas encostam uns com os outros, são susceptíveis de serem mais ricas em diversidade e densidade de espécies que as áreas centrais de qualquer ecossistema. E isso é verdade não só para as zonas adjacentes da seleção natural, mas também para os limites de florestas que perfilam com zonas degradadas, como por exemplo, aquelas que estão ao lado de plantações agrícolas. Existem mais pássaros nas extremidades das florestas do que no centro.

Pesquisas sobre o uso da interdisciplinaridade na resolução de problemas e na produtividade acadêmica sugerem que jovens pesquisadores avançam mais quando têm uma forte vinculação a um campo específico e experiência prévia em pesquisa interdisciplinar colaborativa. Em outras palavras, ser eficaz como um pesquisador interdisciplinar exige não apenas conhecer diferentes campos, mas adquirir habilidades específicas relevantes para ser colaborativo, incluindo a capacidade de trabalhar com outras pessoas que têm maior conhecimento em outras especialidades, e ao mesmo tempo, saber como apresentar um conhecimento próprio, efetivamente, de uso coletivo. Isso tem implicações na forma como os alunos de pós-graduação devem ser capacitados. Eles precisam conhecer bem pelo menos uma linha de pesquisa específica e sentir-se competente nela; eles precisam saber como situar isso em pelo menos um campo de linhas de pesquisa relacionadas e complementares; 
eles precisam saber como trabalhar de forma colaborativa com os outros que sabem utilizar diferentes ferramentas, métodos, linhas de pesquisa empírica e teorias. Trabalhar colaborativamente é uma habilidade a ser desenvolvida, e isso inclui ambos os lados do simples modelo de comunicação emissor-receptor: como fazer-se entender e como entender os outros. Ambos exigem reflexão - examinar suas próprias decisões como premissas e procurar observar os problemas de outras perspectivas.

Poucos na pesquisa em Comunicação duvidam das virtudes da interdisciplinaridade, mas não há consenso quanto ao modelo no qual os programas de Comunicação podem alcançar a interdisciplinaridade, e de fato, cada um dos diferentes subcampos e linhas de trabalho são realmente importantes. Pense novamente em meu exemplo anterior, de modelo de negócios que tem sido impressionantemente bem sucedido, tanto na obtenção de recursos e status, como para alcançar uma identidade e integração interdisciplinar. Ninguém confunde contabilidade com comportamento organizacional, ou análise financeira com administração. Mas como um campo, a área de Negócios tem usado a estrutura dos programas de MBA como uma forma para evoluir uma eficaz definição compartilhada que facilita o reconhecimento de fora (e os recursos que vêm com ele) e o reconhecimento interno. Não há comparativamente modelos compartilhados no campo da Comunicação. Os programas de mestrado são extremamente heterogêneos.

Mas essas não são preocupações meramente intra-acadêmicas. A comercialização do campo da Comunicação é necessariamente uma questão de geração de interesse do estudante - algo em que o campo se afundou como um feliz subproduto do sucesso da mídia, mas que não pode tomar algo como dado. É também uma questão de comercializar estudantes para potenciais empregadores. Quais são as competências ou vantagens que os formados em Comunicação podem ter? E aqui eu incluo os níveis de graduação, mestrado e doutorado - para todos os níveis, não apenas o menor, os departamentos de Comunicação estão formando seus estudantes principalmente para carreiras não-acadêmicas. Isso foi parcialmente mascarado no nível de doutorado com o boom das vagas em novos cursos. Mas isso não é o futuro. 
Há também uma questão importante na forma como os estudantes circulam pelo campo. Ou seja, independentemente da sua concentração dentro dele, como é que eles se sentem sobre o todo? Vai ser algo que lhes manterá em conexão? Deixe-me colocar esta questão especificamente no nível de doutorado. Os doutores em Comunicação são fieis ao campo ou têm um baixo engajamento? Eles continuam vinculados ao campo da Comunicação depois de assumirem postos no governo ou no mercado? Esta é uma questão que poderia ser colocada a muitos campos e com resultados diferentes. Por exemplo, os doutores em Economia e em Psicologia que trabalham fora da academia normalmente se consideram ainda como economistas e psicólogos. Alguns publicam e muitos participam de encontros profissionais mantendo redes com outros doutores em suas áreas. Isto é pouco provável entre sociólogos e cientistas políticos, embora em cada campo haja esforços para tentar incorporar melhor os profissionais não acadêmicos no mundo da pesquisa científica.

Simultaneamente, é importante para os pesquisadores em Comunicação perguntarem-se quem são seus "clientes". Quem são os consumidores e usuários do conhecimento que produzem, quem paga por ele, e como? Até certo ponto, eles podem ser encontrados na própria academia, os leitores de revistas científicas são no fundo outros professores e estudantes de pós-graduação. Mas para a Comunicação, como para qualquer campo acadêmico, uma preocupação vital deve ser pensada sobre as profissões que podem informar, os empregadores que podem contratar os graduados, as arenas políticas nas quais seus conhecimentos podem fazer a diferença, e em que medida eles atingem e informam públicos mais amplos. Isso não é uma estratégia de comunicação para fazer com que qualquer pesquisa seja feita de qualquer maneira e seja publicada na revista acadêmica de maior prestígio, e ter a esperança que Malcolm Gladwell ${ }^{5}$ a descubra e a divulgue.

Vale acrescentar que isso se torna ainda mais importante com a internacionalização da pesquisa em Comunicação. $\mathrm{O}$ campo tem se desenvolvido, como muitos outros, com enormes contribuições

\footnotetext{
${ }^{5}$ Prestigiado colunista da revista The New Yorker, que explora em seus artigos resultados de pesquisas nas Ciências Sociais e na Psicologia (N.T.).
} 
europeias, norte-americanas e australianas (e meu foco tem sido principalmente no contexto norte-americano). Mas há um crescimento rápido da pesquisa em Comunicação em outros lugares, especialmente na Ásia e na América Latina. Em parte porque o campo é mais recente, as disparidades de maturidade representam um fator menor. De qualquer forma, muito do futuro do campo reside na pesquisa no (e sobre o) resto do mundo e na construção de conexões internacionais.

\section{O campo da Comunicação e a transformação da universidade}

Finalmente, antes de terminar, quero dizer algumas palavras sobre o contexto institucional em que a pesquisa em Comunicação está inserida. Alguns membros da ICA trabalham na Microsoft ou no Google, alguns em agências governamentais, alguns em fundações filantrópicas e até mesmo alguns para entidades ativistas, como a Consumers Union ou a Free Press. Mas a maioria trabalha em faculdades e universidades. E devemos levar muito a sério as transformações que estão ocorrendo no ensino superior. Para tentar não ser cansativo, já que esse tema valeria outra conferência, deixem-me ser um pouco telegráfico.

Os orçamentos das universidades mudaram drasticamente nos últimos 35 anos. Quase todo o crescimento líquido está nas escolas profissionalizantes e tecnológicas, além das Ciências da Saúde. Os programas de Comunicação também cresceram muito. Em alguns casos, isso contraria a tendência observada nas Artes e nas Ciências; em outros casos, eles estão seguindo a tendência das escolas profissionalizantes. Mas muitos programas de Comunicação são, na verdade, híbridos - ao menos é assim que são classificados em algumas instituições. E isso lança algumas questões para o futuro.

As bases financeiras para nosso trabalho ganham cada vez mais importância. Isto ocorre porque as universidades estão se organizando de forma a explicitar seus fluxos de caixa, mesmo que algumas vezes distorçam dados contábeis. Isso está ocasionando o fim de algumas formas de angariar recursos. Universidades e faculdades que sempre foram mantidas por subsídios cruzados estão sendo organizadas como empresas lucrativas. Isso significa 
que unidades específicas são avaliadas por aquilo que geram de receita. As vezes podem gerar prestígio, o que pode ser traduzido em dinheiro, atraindo estudantes ou doadores. Mas isso não é igualmente verdadeiro para todas as áreas.

O financiamento externo é muito importante, e em alguns casos, serve também como um indicador de prestígio. Universidades confessionais, como as de Nebraska e de Syracuse, vêm sendo expulsas da elite da Associação Americana de Universidades por não receberem financiamento suficiente das agências de fomento de maior prestígio. Isso é uma questão ligada principalmente a bolsas de estudo. Subvenções de pesquisas são tão valiosas quanto dinheiro, mas não tanto quanto uma fonte com prestígio. Porém, onde isso é baseado em convênios com patrocinadores corporativos, a administração central pode se impressionar. E, claro, isso também pode impressionar os estudantes que esperam vagas para trabalhar em tais corporações (e com razão, uma vez que os estágios e os convênios muitas vezes abrem portas). Doações, é claro, são sempre bem-vindas.

É doloroso utilizar termos de mercado para avaliar alguns programas pelo valor do que recebem por seu prestígio, enquanto outros são avaliados pelo que desembolsam. Basta dizer que os programas de Comunicação são mais frequentemente pagadores do que recebedores no mercado de subsídios cruzados. Não há muitas escolas onde, digamos, professores de Física trabalhem mais com o objetivo de subsidiar os pesquisadores em Comunicação. O elevado número de matrículas melhora os argumentos para se receber mais recursos, mas também aumentar a probabilidade de vir a ser tratado como uma árvore de dinheiro, a menos que seja possível convencer os administradores de que isso trás prestígio e reconhecimento externo.

$\mathrm{Na}$ maioria das vezes (e na maioria das instituições fora da alta elite), os salários dos professores de Comunicação dependem da quantidade de matrículas na graduação. Isso ocorre em diferentes estruturas de ensino à base de horas-aula, sejam em universidades privadas ou públicas, que recebem financiamentos do Estado a partir de uma fórmula de contagem por proporção professor/aluno. Isso significa que a maioria dos professores de Comunicação 
(principalmente de instituições que se dedicam mais a pesquisa e menos à formação profissionalizante) estão em última instância no mesmo barco que os colegas das Ciências Humanas e Sociais. Em todos esses campos, com raras exceções na Economia, as matrículas na graduação pagam as contas. $\mathrm{O}$ crescimento de programas de Comunicação é básico para a abertura de novas vagas de docentes, mas também para a abertura de turmas cada vez maiores e, em alguns lugares maiores cargas de horas-aula. Isto levanta questões estratégicas: o quanto devemos abraçar o ensino de graduação como uma missão definitiva; o quanto os programas devem ser direcionados para atrair alunos; ou em vez disso, o que devemos fazer para tentar escapar da relação matrícula/dependência na competição por prestígio?

$\mathrm{O}$ aumento das matrículas reflete em parte o entusiasmo pelas novas mídias e o reconhecimento da centralidade da comunicação em geral para o futuro da sociedade. Alguns crescimentos recentes refletem o boom dos Estudos Culturais no final do século 20 (e também pelo fato de que nos EUA eles foram rejeitados pela maioria das Ciências Sociais, deixando espaço para programas de Comunicação complementarem uma tendência com raízes nos programas tradicionais das Humanidades). Mas a grande maioria das matrículas nos departamentos de Comunicação também refletem muito as aspirações dos estudantes para seguirem carreira nos meios de comunicação.

Não seria de surpreender que um jovem de 18 anos não saiba muito sobre a estrutura das carreiras profissionais, de qualquer forma, isso tem mudado rapidamente. Não há mais clareza sobre estabelecer as "comunicações" como um campo profissional ou como um campo de pesquisa. Se aproxima dos Negócios, como nos cursos de Relações Públicas ou de Comunicação Organizacional? Esta mais perto das Artes, com os estudos de representação/interpretação e produção midiática? $\bigcirc$ futuro do Jornalismo está fadado a ser o legado do declínio da mídia? Ou há um futuro no qual um analista teórico da mídia terá um emprego bem remunerado?

Os programas de Comunicação vivem na constante tensão entre o que os alunos querem estudar e o que seus professores querem ensinar. Isso é solucionado com diferentes graus de acordos 
de cavalheiros, compromissos e má-fé. Mas o tema é importante. Para além da questão de como alunos de graduação são formados, há a questão de como as estruturas curriculares compreendem o campo. Ela molda as percepções externas, e influencia inclusive na ocupação das vagas.

Isto conduz a uma outra tensão, pois os programas de Comunicação usam muitos professores de outros departamentos ou temporários. Isso reflete no crescimento e no tamanho das turmas (que também influencia em como a Comunicação é vista em "termos de mercado" pelo o resto da universidade), e na preferência de professores por cursos mais avançados. Mas isso também reflete nas disciplinas que os estudantes querem, e que o corpo docente não está preparado para ensinar. Muitas delas estão no lado "profissionalizante" do currículo. E para isso os professores temporários podem ser excelentes. Na maioria das vezes, eles ocupam cargos importantes no mercado midiático. Alguns não ensinam pelo dinheiro e não são nem bem remunerados. $\mathrm{O}$ campo da Comunicação é influenciado pela distância crescente entre os professores efetivos e o grande número de colegas mais jovens em funções temporárias e com futuro incerto.

Esse problema pode aumentar com a possibilidade de que o recente crescimento no número de matrículas não continuará para sempre. A chegada de alunos que procuram carreiras de comunicação vagamente conceituados pode não ser infinita. Pode haver mais discriminação com base na existência de cursos realmente capazes de garantir os empregos que eles querem. E os programas podem ser pressionados para direcionarem mais professores para disciplinas profissionalizantes que atendam aos alunos. Este é um problema até para as escolas e departamentos que compreendem-se como primeiramente para a formação profissional e pré-profissional. Isto levanta questões sobre que tipos de pesquisas são relevantes para a educação profissionalizante, e como a pesquisa relevante pode ser atraente para os alunos que não vêem a sua relação com a capacitação profissional. A questão se torna mais grave para os programas que compreendem-se mais em termos acadêmicos. O futuro da pesquisa de Comunicação estará em risco se for para ser financiada intei- 
ramente com base na matrícula de estudantes que não estão muito interessados em pesquisa.

\section{Conclusão}

Para encerrar, deixe-me voltar a meus temas principais e a alguns pensamentos muito limitados sobre o que pode ser feito.

A Comunicação é de central importância. Felizmente, muitas das questões estudadas pelo campo da investigação em Comunicação não são apenas importantes, mas são também cada vez mais reconhecidas como importantes. Alterações nos padrões e nos meios de comunicação esclarecem cada vez mais dimensões-chave de mudanças global. Este campo literalmente estuda os rumos de como o mundo é feito.

Meu tema principal foi a heterogeneidade da pesquisa em Comunicação. Eu argumentei que isso não é uma coisa ruim, é até bom, mas não deixa de ser um desafio. Isso envolve:

- O reconhecimento do campo para receber recursos externos - a partir de outros campos acadêmicos, de fundações e das empresas que podem empregar os formandos.

- A coerência interna do campo e a capacidade de manter elevados padrões de trabalho intelectual.

- A natureza das relações entre as pesquisas em Comunicação e trabalhos em outros campos.

Enquanto eu não prevejo nenhuma resolução fácil para os dilemas de ser uma disciplina, um campo interdisciplinar e uma profissão, eu argumentei que a pressão sobre os pesquisadores de Comunicação para oferecer uma imagem coerente do campo vai crescer.

Neste campo heterogêneo, o que é necessário não é uma pressão para a conformidade, mas a produção de mais e melhores ligações entre as diferentes linhas de trabalho. Sugeri que a teoria tem um papel especial a desempenhar nisso tudo, mas colocar as grandes questões que conectam diferentes linhas de trabalho é um problema que excede em muito o domínio da teoria. Então, o que deve ser feito? Bem, para começar: 
- Criar maneiras para que os jovens pesquisadores se conectem uns aos outros em todas as escolas, criando linhas de trabalho, metodologias e temas de pesquisa conjuntos. Isso pode ser por meio de bolsas de estudo, workshops, encontros - mas a chave são as conexões laterais. Isso deve servir como uma motivação para apoiar jovens pesquisadores em um momento em que o mercado de trabalho já está fazendo isso, bem, com suas imperfeições.

- Reconhecer o valor de síntese e de debate que ajudam a tornar claro o estado da arte em diferentes subcampos, e a dar uma melhor cobertura do campo em geral. Isso pode vir por meio de relatórios anuais, revistas ou recursos de informação eletrônica (nós tentamos um pequeno exemplo disso no site do Conselho de Pesquisa em Ciências Sociais - www.ssrc.org/ - com o tema da esfera pública). Essas exigências são recompensadas com boas sínteses - e debates - assim como a produção de novos (e fragmentados) conhecimentos. E boas sínteses são também a base para que uma boa pesquisa receba o devido reconhecimento.

- Iniciar uma conversa sobre os modelos de níveis e estruturas organizacionais (ou renová-los, se já existirem). Há sempre os posicionamentos locais em cada instituição que fazem as mudanças parecem impossíveis.

Mas também há a compreensão de que o campo precisa desenvolver um respeitável conjunto de instituições.

- Comecem a fazer uma busca ativa de conexões interdisciplinares em torno de questões sociais. As comunicações tiveram um papel central na primavera árabe? Não apenas se felicitem rapidamente por descobrirem isso, criem laços com os estudos do Oriente Médio e as Ciências Política. Programas em Estudos Internacionais, Estudos Ambientais e Estudos de Políticas Públicas estão crescendo junto com os de Comunicação; conexões mais próximas deveriam estar crescendo também. Não tenham a interdisciplinaridade como algo dado, só porque a Comunicação sempre 
teve um excesso disso. De qualquer forma, ela irá diminuir com a criação de novas interrelações, pois é preciso renovação constante.

- Certifiquem-se que a discussão interna não se desenvolva apenas sobre "o que é o campo da Comunicação", mas sobre os importantes problemas intelectuais e práticos para os quais os pesquisadores de Comunicação podem gerar um conhecimento necessário.

Minhas sugestões são muito menores do que minhas análises, e das que são necessárias. Mas o campo de pesquisa em Comunicação é a prova de que vários pequenos disparos podem ter um impacto enorme. O trabalho no campo é importante; pelo menos é, na maioria das vezes, perspicaz; e isso está na vanguarda da compreensão do que está acontecendo a nosso mundo, assim como o trabalho em qualquer das Ciências Sociais.

Recebido: 10.10 .2011

Aceito: 25.4.2012

N.T.: $O$ texto deriva da conferência de abertura do $61^{\circ}$ Congresso da International Communication Association, realizado em maio de 2011 na cidade de Boston, Estados Unidos. As ponderações, análise e conselhos de Graig Calhoun caíram como um balde de água fria sobre os mais de mil e quinhentos pesquisadores presentes na abertura do Congresso da ICA. Como um irmão mais velho, ele deu aquele necessário puxão de orelhas no caçula que "já se acha". Começando com um choque ao usar ironicamente a Wikipédia como fonte, ele desenvolve seus argumentos sobre as vantagens, desvantagens, limites e avanços dos estudos em Comunicação como uma interdisciplina, desembolando o emaranhado conceitual relativo ao campo, lembrando que vários outros já passaram (e continuam passando) pela mesma crise existencial. Sendo uma das principais, a crise de identidade, na qual tenta se definir como mais voltado para a formação profissionalizante ou para a reflexão e a pesquisa.Trata-se de um texto de fundamental importância que reproduz a maioria dos anseios vivenciados cotidianamente por todos nós em reuniões de departamentos, publicações, congressos ou em listas de discussão de grupos de pesquisa e entidades científicas da Comunicação. Os leitores da Revista Intercom se pegarão lendo em voz alta partes do texto como se fossem pensamentos próprios, mas que no fundo pertencem a um lúcido irmão 
mais velho, que sempre tem muito a nos ensinar. Versão em inglês publicada no International Journal of Communication, v. 5, disponível em: http://ijoc.org/ ojs/index.php/ijoc/article/view/1331/622 . Copyright (C) 2011 (Craig Calhoun, calhoun@ssrc.org). Licenciado sob Creative Commons - Atribuição, Uso não comercial, Vedada e criação de obras derivadas (BY-NC-ND). 